\title{
Prevalence of nasal symptoms and their relation to self-reported asthma and chronic bronchitis/emphysema
}

\section{To the Editor:}

We read with interest the paper by MonTNÉMERY et al. [1] reporting nasal symptoms in patients with asthma and chronic bronchitis/emphysema (CBE). This study is of particular interest since it is the first, to our knowledge, to assess nasal symptoms in CBE. It seems that the results can be interpreted since an agreement of $\sim 70 \%$ was found between the diagnosis of asthma or CBE made in the study and a doctor's diagnosis. However, some patients with $\mathrm{CBE}$ may be falsely classified and may have other respiratory diseases, including asthma. Moreover, patients aged 29 yrs are unlikely to have CBE and the authors showed, in another paper [2], that the prevalence of $\mathrm{CBE}$ was 3.3\% in subjects aged between 20-29 yrs. In order to reinforce the results of the study, it would have been interesting to study the association of nasal symptoms with asthma and $\mathrm{CBE}$ depending on the age groups.

A second point, regarding this study may be discussed. The characteristics of nasal symptoms appear to differ in asthma and CBE. In their first paper, MONTNÉMERY et al. [2] reported "allergic eyenose catarrh (hay fever)". It would also be interesting to discuss this association with asthma and CBE.

Finally the authors reported that nasal symptoms probably due to nonallergic mechanisms (provoked by cold air/damp air) were significant risk factors for asthma. This is in accordance with the results from an analysis of the European Community Respiratory Health Survey data, showing that rhinitis is associated with an increased risk of asthma in nonatopic subjects with normal immunoglobulin-E levels [3].

\section{J. Bousquet*, B. Leynaert ${ }^{\#}$, F. Neukirch ${ }^{\#}$ \\ *CHU Montpellier and ${ }^{\#}$ INSERM U 408, France.}

\section{References}

1. Montnemery P, Svensson C, Adelroth E, et al. Prevalence of nasal symptoms and their relation to self-reported asthma and chronic bronchitis/emphysema. Eur Respir J 2001; 17: 596-603.

2. Montemery $\mathrm{P}$, Adelroth $\mathrm{E}$, Heuman $\mathrm{K}$, et al. Prevalence of obstructive lung diseases and respiratory symptoms in southern Sweden. Respir Med 1998; 92: 1337-1345.

3. Leynaert B, Bousquet J, Neukirch C, Liard R, Neukirch F. Perennial rhinitis: an independent risk factor for asthma in nonatopic subjects: results from the European Community Respiratory Health Survey. J Allergy Clin Immunol 1999; 104: 301-304.
From the authors:

We are grateful for these comments on our observations [1] regarding the potential involvement of nasal disease in asthma as well as chronic bronchitis/ emphysema (CBE), and also for bringing to our attention the interesting report [2] on the identification of perennial rhinitis as an independent risk factor for nonatopic asthma. Incidentally, we have just finalized a second survey involving 9,300 responding subjects $[3,4]$ confirming our original observations [1]. We think our findings may broaden the interest, not only in treating the nasal passages in patients suffering from different forms of obstructive airway diseases but also in using the human nose for safe and wellcontrolled studies of inflammatory responses of the human respiratory tract mucosa [5].

As suggested by Bousquet and colleagues we have now reanalysed our nasal symptom data with respect to different age groups. Thick yellow nasal discharge characteristically remains a risk factor for CBE $(p<0.004-0.02)$ but not for asthma $(p>0.05)$ in all age groups. Conversely, sneezing and/or itching remain exclusive risk factors for asthma $(\mathrm{p}<0.001-0.03)$ in all but the eldest age group (50-59 yrs). These findings strengthen our notion that the nasal symptomatology adds to the different nature of the two bronchial diseases. In response to the second point raised by Bousquet and colleagues our current analysis showed that self-reported "allergic eye-nose catarrh" was twice as common among subjects with self-reported asthma $(14.5 \%)$ compared to subjects with self-reported CBE (7.3\%). This observation agrees with our finding that symptom-provoking factors of an allergic nature were risk factors for asthma rather than CBE [1].

Importantly, we also demonstrated that exposure to nonallergic factors in general were more of a risk factor for chronic bronchitis/emphysema than for asthma [1].

\section{C.G.A. Persson*, P. Montnémery}

Depts of *Clinical Pharmacology and Occupational Therapy, University Hospital Lund, Sweden.

\section{References}

1. Montnémery $\mathrm{P}$, Svensson $\mathrm{C}$, Ädelroth $\mathrm{E}$, et al. Prevalence of nasal symptoms and their relation to self-reported asthma and chronic bronchitis/emphysema. Eur Respir J 2001; 17: 596-603.

2. Leynaert B, Bousquet J, Neukirch C, Liard R, Neukirch F. Perennial rhinitis: An independent risk 
factor for asthma in nonatopic subjects. $J$ Allergy Clin Immunol 1999; 104: 301-304.

3. Montnémery P, Nihlén U, Löfdahl CG, et al. The association between asthma, chronic bronchitis/ emphysema and rhinitis. Eur Respir $J$ 2001; 18: Suppl. 33, 201s.
4. Andersson $\mathrm{M}$, Nihlén $\mathrm{U}$, Greiff $\mathrm{L}$, et al. Allergic rhinitis prevalence and incidence in southern Sweden 1992-2000. Eur Respir J 2001; 18: Suppl. 33, 200s.

5. Persson CGA, Svensson C, Greiff L, et al. The use of the nose to study the inflammatory response of the respiratory tract. Thorax 1992; 47: 993-1000. 